\title{
Current heterosexual marriage is associated with significantly decreased levels of anxiety symptoms among Chinese men who have sex with men
}

Zuosen Yang ${ }^{1,2+}$, Shuang $\mathrm{Li}^{1,2+}{ }^{+}$, Rui Zhang ${ }^{1,2}$, Jun $\mathrm{Na}^{1,2}$, Yanxia $\mathrm{Li}^{1,2}$, Huijuan Mu ${ }^{1,2}$, Liya Y Yu ${ }^{1,2}$, Li Liu ${ }^{1,2}$, Wei Sun ${ }^{1,3}$, Guowei Pan ${ }^{1,3}$ and Lingjun Yan ${ }^{1,3^{*}}$

\begin{abstract}
Background: The high heterosexual marriage rate could be a 'double-edge' sword for the emotional health of Chinese men who have sex with men (MSM). The aim of this study was to determine if current marriage and breakdown of marriage (divorce) have different effects on the mental health of Chinese MSM.

Methods: Eight hundred seven MSM were recruited using respondent-driven sampling from four cities in northeastern China. Gay-related stressful events (GRSE) were measured using the Gay Related Stressful Life Events Scale; social support was measured by the Social Support Rating Scale (SSRS); and depressive and anxiety symptoms were assessed using the Self-Rating Depression Scale (SDS) and Self-Rating Anxiety Scale (SAS), respectively.
\end{abstract}

Results: Of the study participants, $13.4 \%$ were married to women and $4.5 \%$ were divorced. The rates of marriage or divorce were 35.3 and $75.8 \%$ for participants $30-39$ and $>40$ years of age, respectively. The current married MSM had the highest SDS $(50.0 \pm 10.9)$ and SSRS $(35.8 \pm 8.6)$ levels, but the lowest SAS $(38.7 \pm 12.1)$ levels. Divorced MSM had the highest SAS $(44.4 \pm 9.6)$ and lowest SSRS $(30.8 \pm 8.1)$ levels. Age, GESE number, and HIV infection were predictors for SDS and SAS, and current marriage was associated with significantly decreased level of SAS ( $\beta=-$ $0.136, P=0.001$ ) based on multiple linear analysis.

Conclusions: Current marriage is associated with significantly decreased levels of anxiety symptoms among Chinese MSM. More studies are needed to understand the mechanisms underlying the effects of different marriage status on the emotional distress of Chinese MSM.

Keywords: Men who have sex with men, Marriage, Anxiety symptoms

* Correspondence: ljyan@cmu.edu.cn

†Zuosen Yang and Shuang Li contributed equally to this work.

${ }^{1}$ Institute of Preventive Medicine, China Medical University, Shenyang

110122, China

${ }^{3}$ Research Center for Universal Health, School of Public Health, China Medical University, No. 77 Puhe Road, Shenyang North New Area, Shenyang 110122, Liaoning, China

Full list of author information is available at the end of the article

\section{Background}

Marriage between males is illegal and traditional Chinese values require boys to "have a son to carry on the family name", especially after the one child-one family policy was implemented in the early 1970s in China. Among Chinese men who have sex with men (MSM), most are only children who face more stress to honor their duty to their parents and to follow the social norms more

(c) The Author(s). 2020 Open Access This article is licensed under a Creative Commons Attribution 4.0 International License, which permits use, sharing, adaptation, distribution and reproduction in any medium or format, as long as you give appropriate credit to the original author(s) and the source, provide a link to the Creative Commons licence, and indicate if changes were made. The images or other third party material in this article are included in the article's Creative Commons licence, unless indicated otherwise in a credit line to the material. If material is not included in the article's Creative Commons licence and your intended use is not permitted by statutory regulation or exceeds the permitted use, you will need to obtain permission directly from the copyright holder. To view a copy of this licence, visit http://creativecommons.org/licenses/by/4.0/. The Creative Commons Public Domain Dedication waiver (http://creativecommons.org/publicdomain/zero/1.0/) applies to the data made available in this article, unless otherwise stated in a credit line to the data. 
than their counterparts in other countries $[1,2]$. To avoid the stigma and discrimination associated with homosexuality and to cope with the stressors from family and society, many Chinese MSM marry and conceal their same-sex behaviors from their wives and members of their broader social network [1-4]. Between one-fourth and one-third of Chinese MSM marry women $[3,4]$ and most keep their homosexuality a secret [1]. The marriage rate is significantly higher in Chinese MSM than MSM in Western countries (3-5\%) $[5,6]$. Such a choice, however, could be a 'double-edge' sword. On the one hand, marrying a woman and having a child would mask homosexual behaviors, meet social expectations, avoid being "outed" to the family, buffer the stressors from parents and family, and avoid experiencing guilt, shame, and anxiety concerning homosexual behaviors [7-9]. A few studies have shown that keeping homosexual behaviors a secret could reduce the frequency of gay-related stressful events (GRSEs) among MSM [10, 11], but no studies have reported if such a defensive choice could reduce the levels of depression or anxiety symptoms for married MSM. On the other hand, this strategy will result in numerous new problems with significant byproducts for the mental health of MSM [7-9, 12]. The high level of internal gender role conflict (GRC) stemming from the desire for male partners while living with a wife without personal enthusiasm, fear about being known or disclosing their homosexual orientation and behaviors, and risks of transmitting HIV to their wives and girlfriends [13] all will increase psychological distress and reduce self-esteem. Several studies have reported depression, anxiety, sexual abuse, and other psychological syndemics among MSM in China [11, 14], only a few studies have assessed associations between high marriage rates and emotional health $[15,16]$. Therefore, whether or not married and/or divorced MSM have significantly higher depression and/or anxiety symptoms than un-married MSM has not been established. The present study aimed to determine the following: (1) if current marriage is associated with significantly decreased levels of anxiety symptoms; (2) marriage to a woman may worsen the emotional status, particularly depression symptoms; (3) the dissolution of a marriage will influence the emotional health and increase and/or decrease the levels of anxiety and depression symptoms.

\section{Methods}

\section{Subjects}

The locations of the cross-sectional study areas and selection of MSM were described previously $[11,17]$. In brief, 807 MSM who lived or worked in four cities of Liaoning Province in northeastern China were recruited using a standardized respondent-driven sampling (RDS) procedure in 2012. Respondents were included if they had oral or anal sexual relations with another man during the previous 12 months. Each subject was interviewed personally by trained interviewers. Sociodemographic characteristics, marriage status, sexual identity, and disclosure of homosexual identity were recorded using a structured questionnaire [17].

\section{Definition of variables}

The following socio-demographic factors were recorded: age, education ( $<10$ years, $10-12$ years, $\geq 13$ years), sexual identity (homosexual, bisexual, heterosexual, unconfirmed), marital status (single, cohabitation with a female partner, married, divorced), disclosure of homosexual identity to parents or wife (yes/no).

\section{Anxiety and depressive symptoms}

Subjective feelings of depression and anxiety during the week prior to the interview were quantified using the Self-Rating Depression Scale (SDS) [18] and the SelfRating Anxiety Scale (SAS) [19]. The details of SDS and SAS has been described in previous paper of the study [17]. Depression and anxiety was defined as scores of SDS over 53 and SAS over 50 [20, 21].

\section{Social support}

Social support was measured by the Social Support Rating Scale (SSRS) [22], which contains 10 items and measures 3 dimensions of social support: subjective support (4 items), objective support (3 items), and supportseeking behavior (3 items). SSRS scores were added up to generate a score of 0 to 50 , with a higher score indicating stronger social support. The SSRS has been used with a wide range of Chinese populations due to its high reliability and validity, and the 2 -monthtest-retest reliability of 0.92 .

\section{Gay-related stressful life events}

GRSEs were measured using the Gay Related Stressful Life Events Scale [23], a 12-item scale that measures the occurrence of incidents related to sexual orientation over the past 3 months. The detailed of SDS and SAS has been described in previous paper [17].

\section{Statistical methods}

Data analysis was conducted using SPSS (version 17.0). Analysis of variance (ANOVA) and the Kruskal-Wallis test were used to compare mean values of SAS, SDS, SSRS, and GRSEs by demographic characteristics and marriage status. We used stepwise multivariable linear regression analysis retaining variables with a $p$ value $<$ 0.10 to assess which variables were independently associated with SDS and SAS scores. Age, education, income, 
sexual orientation, disclosure of homosexual identity, number of GRSE, SSRS score, and HIV infection were included in the stepwise selection procedure.

\section{Results}

Table 1 shows that a total of 807 MSM were recruited with the following demographics: $71.3 \%$ were $<30$ years of age; $40.3 \%$ were bisexual; $47.2 \%$ were gay; $13.4 \%$ were married to women; $4.5 \%$ have divorced; $22.9 \%$ revealed their homosexual identities to their parents and wives; $26.0 \%$ experienced GRSEs in the past 3 months; and $3.5 \%$ were HIV-positive. The marriage and divorce rates (MD) increased rapidly with age and decreased significantly with decreasing education years, which were 35.3 and $75.8 \%$ for those $30-39$ and $>40$ years of age, respectively, and were significantly higher in those who were HIV-positive (39.3\%) than in those who were HIVnegative (17.1\%), and significantly lower in those who had disclosed homosexual status (9.2\%) than in those who had not disclosed homosexual status (20.4\%).
Table 2 shows that the SDS means increased significantly with age and decreased significantly with education level. The SSRS score showed an opposite linear trend, unlike the SAS score. When sexual identity was considered, gay had the highest SDS, SAS, and GRSEs means and heterosexual MSM had the lowest levels. When marriage status was considered, the married MSM had the highest SDS and SSRS and lowest SAS, and divorced MSM had the highest SAS and lowest GRSEs and SSRS. The SDS and SAS means were significantly elevated among MSM with HIV infection. The SAS level was borderline increased, but GRSEs levels were significantly decreased, for those who disclosed their sexual identity to others.

Table 3 shows that age, GRSE number, and HIV infection were predictors for SDS and SAS, SSRS $(\beta=-0.242$, $p<0.001)$ and higher education years $(\beta=-0.119$, $p<0.001)$ were associated with significantly decreased levels of SDS. Sexual identity as gay $(\beta=0.076, p=0.031)$ and current marriage $(\beta=-0.136, p=0.001)$ were significant predictors for SAS.

Table 1 Distribution of marriage status of 807 MSM sampled

\begin{tabular}{|c|c|c|c|c|c|c|c|c|c|c|c|c|c|}
\hline & \multirow[t]{2}{*}{$\mathrm{N}$} & \multirow[t]{2}{*}{$\%$} & \multicolumn{2}{|c|}{ Single } & \multicolumn{2}{|c|}{ Cohabitation } & \multicolumn{2}{|c|}{ Married with female } & \multicolumn{2}{|c|}{ Divorced } & \multicolumn{2}{|c|}{$M+D$} & \multirow[t]{2}{*}{$\mathrm{p}$} \\
\hline & & & $\mathrm{N}$ & $\%$ & $\mathrm{~N}$ & $\%$ & $\mathrm{~N}$ & $\%$ & $\mathrm{~N}$ & $\%$ & $\mathrm{~N}$ & $\%$ & \\
\hline \multicolumn{14}{|l|}{ Age, years } \\
\hline $18-29$ & 575 & 71.3 & 492 & 85.6 & 61 & 10.6 & 20 & 3.5 & 2 & 0.3 & 22 & 3.8 & \multirow[t]{3}{*}{$<0.001$} \\
\hline $30-39$ & 133 & 16.5 & 66 & 49.6 & 20 & 15.0 & 38 & 28.6 & 9 & 6.8 & 47 & 35.3 & \\
\hline $40-64$ & 99 & 12.3 & 13 & 13.1 & 11 & 11.1 & 50 & 50.5 & 25 & 25.3 & 75 & 75.8 & \\
\hline \multicolumn{14}{|l|}{ Education, years } \\
\hline$<10$ & 255 & 31.6 & 164 & 64.3 & 32 & 12.5 & 40 & 15.7 & 19 & 7.5 & 59 & 23.1 & \multirow[t]{3}{*}{0.055} \\
\hline $10-12$ & 322 & 39.9 & 235 & 73.0 & 34 & 10.6 & 43 & 13.4 & 10 & 3.1 & 53 & 16.5 & \\
\hline$\geq 13$ & 230 & 28.5 & 172 & 74.8 & 26 & 11.3 & 25 & 10.9 & 7 & 3.0 & 32 & 13.9 & \\
\hline \multicolumn{14}{|l|}{ Sexual identity } \\
\hline Gay & 381 & 47.2 & 281 & 73.8 & 45 & 11.8 & 36 & 9.4 & 19 & 5.0 & 55 & 14.4 & \multirow[t]{4}{*}{0.187} \\
\hline Heterosexual & 13 & 1.6 & 10 & 76.9 & 1 & 7.7 & 2 & 15.4 & 0 & 0.0 & 2 & 15.4 & \\
\hline Bisexual & 325 & 40.3 & 219 & 67.4 & 34 & 10.5 & 57 & 17.5 & 15 & 4.6 & 72 & 22.2 & \\
\hline Unconfirmed & 88 & 10.9 & 61 & 69.3 & 12 & 13.6 & 13 & 14.8 & 2 & 2.3 & 15 & 17.0 & \\
\hline \multicolumn{14}{|c|}{ Disclosure of homosexual identity } \\
\hline No & 622 & 77.1 & 433 & 69.6 & 62 & 10.0 & 97 & 15.6 & 30 & 4.8 & 127 & 20.4 & \multirow[t]{2}{*}{0.001} \\
\hline Yes & 185 & 22.9 & 138 & 74.6 & 30 & 16.2 & 11 & 5.9 & 6 & 3.2 & 17 & 9.2 & \\
\hline \multicolumn{14}{|l|}{ GRSE } \\
\hline No & 597 & 74.0 & 418 & 70.0 & 63 & 10.6 & 86 & 14.4 & 30 & 5.0 & 116 & 19.4 & \multirow[t]{2}{*}{0.168} \\
\hline Yes & 210 & 26.0 & 153 & 72.9 & 29 & 13.8 & 22 & 10.5 & 6 & 2.9 & 28 & 13.3 & \\
\hline \multicolumn{14}{|l|}{ HIV } \\
\hline No & 779 & 96.5 & 555 & 71.2 & 91 & 11.7 & 100 & 12.8 & 33 & 4.2 & 133 & 17.1 & \multirow[t]{3}{*}{0.020} \\
\hline Yes & 28 & 3.5 & 16 & 57.1 & 1 & 3.6 & 8 & 28.6 & 3 & 10.7 & 11 & 39.3 & \\
\hline All & 807 & 100.0 & 571 & 70.8 & 92 & 11.4 & 108 & 13.4 & 36 & 4.5 & 144 & 17.8 & \\
\hline
\end{tabular}


Table 2 Comparison of average levels of anxiety, depression, number of gay-related stressful events, and social support by demographic factors

\begin{tabular}{|c|c|c|c|c|c|c|c|c|c|c|c|c|}
\hline \multirow[t]{2}{*}{ Risk Factor } & \multicolumn{3}{|l|}{ SDS } & \multicolumn{3}{|l|}{ SAS } & \multicolumn{3}{|l|}{ GRSES } & \multicolumn{3}{|l|}{ SSRS } \\
\hline & Mean & SD & $p$ value & Mean & SD & $p$ value & Mean & SD & $p$ value & Mean & SD & $p$ value \\
\hline \multicolumn{13}{|l|}{ Age, years } \\
\hline $18-29$ & 46.2 & 11.2 & $<0.001$ & 40.5 & 8.4 & 0.029 & 0.4 & 0.7 & 0.050 & 34.2 & 7.0 & 0.220 \\
\hline $30-39$ & 48.3 & 11.3 & & 39.7 & 8.2 & & 0.3 & 0.6 & & 33.8 & 8.4 & \\
\hline $40-64$ & 52.0 & 11.1 & & 42.8 & 13.4 & & 0.2 & 0.5 & & 32.8 & 8.7 & \\
\hline P linearity & $<0.001$ & & & 0.105 & & & 0.015 & & & 0.090 & & \\
\hline \multicolumn{13}{|l|}{ Education, years } \\
\hline$<10$ & 49.3 & 11.1 & $<0.001$ & 40.9 & 9.5 & 0.577 & 0.5 & 1.0 & 0.369 & 32.2 & 7.1 & $<0.001$ \\
\hline $10-12$ & 47.7 & 11.6 & & 40.2 & 8.9 & & 0.4 & 0.8 & & 34.3 & 7.5 & \\
\hline$\geq 13$ & 44.4 & 10.9 & & 41.0 & 9.3 & & 0.5 & 0.9 & & 35.6 & 7.4 & \\
\hline P linearity & $<0.001$ & & & 0.975 & & & 0.679 & & & $<0.001$ & & \\
\hline \multicolumn{13}{|l|}{ Sexual identity } \\
\hline Gay & 47.6 & 11.3 & 0.603 & 41.7 & 8.9 & 0.014 & 0.5 & 1.0 & 0.053 & 33.9 & 7.5 & \\
\hline Heterosexual & 45.6 & 10.0 & & 39.0 & 8.3 & & 0.4 & 1.1 & & 35.2 & 9.9 & \\
\hline Bisexual & 47.4 & 11.5 & & 39.5 & 9.2 & & 0.3 & 0.8 & & 34.2 & 7.5 & \\
\hline Unconfirmed & 45.9 & 11.5 & & 40.5 & 10.2 & & 0.4 & 0.7 & & 33.5 & 6.5 & \\
\hline \multicolumn{13}{|l|}{ Marriage } \\
\hline Single & 46.3 & 11.3 & 0.003 & 40.6 & 8.4 & 0.003 & 0.4 & 0.9 & 0.319 & 34.0 & 7.1 & $<0.001$ \\
\hline Cohabitation & 49.2 & 11.6 & & 42.2 & 9.4 & & 0.4 & 1.0 & & 33.0 & 7.3 & \\
\hline Married with female & 50.0 & 10.9 & & 38.7 & 12.1 & & 0.5 & 1.0 & & 35.8 & 8.6 & \\
\hline Divorced & 49.3 & 12.5 & & 44.4 & 9.6 & & 0.2 & 0.6 & & 30.8 & 8.1 & \\
\hline \multicolumn{13}{|l|}{ HIV positive } \\
\hline Yes & 53.4 & 12.3 & 0.004 & 45.6 & 16.1 & 0.004 & 0.6 & 1.3 & 0.300 & 34.0 & 7.4 & 0.670 \\
\hline No & 47.1 & 11.3 & & 40.5 & 8.8 & & 0.4 & 0.9 & & 34.6 & 9.3 & \\
\hline \multicolumn{13}{|c|}{ Disclosure of homosexual identity } \\
\hline Yes & 46.8 & 11.6 & 0.472 & 41.8 & 10.0 & 0.052 & 0.7 & 1.2 & $<0.001$ & 34.1 & 7.7 & 0.740 \\
\hline No & 47.4 & 11.3 & & 40.3 & 8.9 & & 0.4 & 0.8 & & 34.0 & 7.5 & \\
\hline All & 47.3 & 11.4 & & 40.7 & 9.2 & & 0.4 & 0.9 & & 34.0 & 7.5 & \\
\hline
\end{tabular}

SDS Self-rating depression score, SAS Self-rating anxiety score, SSRS Social support rating score, GRSE Gay related stressful event

Table 3 Multivariable linear regression analysis assessing factors independently associated with SDS and SAS

\begin{tabular}{|c|c|c|c|c|c|c|c|c|}
\hline \multirow[b]{3}{*}{ Age } & \multicolumn{4}{|l|}{ SDS } & \multicolumn{4}{|l|}{ SAS } \\
\hline & \multirow{2}{*}{$\begin{array}{l}\text { Beta } \\
0.145\end{array}$} & \multicolumn{2}{|l|}{$95 \% \mathrm{Cl}$} & \multirow{2}{*}{$\begin{array}{l}\frac{p \text { value }}{<0.001} \\
<0\end{array}$} & \multirow{2}{*}{$\begin{array}{l}\text { Beta } \\
0.117\end{array}$} & \multicolumn{2}{|l|}{$95 \% \mathrm{Cl}$} & \multirow{2}{*}{$\frac{p \text { value }}{0.003}$} \\
\hline & & 0.104 & 0.274 & & & 0.041 & 0.207 & \\
\hline GRSE number & 0.148 & 1.431 & 3.701 & $<0.001$ & 0.155 & 1.217 & 3.135 & $<0.001$ \\
\hline HIV positive & 0.083 & 1.131 & 9.156 & 0.012 & 0.097 & 1.481 & 8.293 & 0.005 \\
\hline SSRS score & -0.242 & -0.468 & -0.268 & $<0.001$ & & & & \\
\hline Education $\geq 13$ year (Ref < 10 year) & -0.119 & -4.639 & -1.348 & $<0.001$ & & & & \\
\hline Gay (ref: HU) & & & & & 0.076 & 0.128 & 2.657 & 0.031 \\
\hline Current marriage with female (ref: single) & & & & & -0.136 & -5.775 & -1.531 & 0.001 \\
\hline
\end{tabular}

HU Sexual identity as heterosexual or unconfirmed 


\section{Discussion}

The rates of MD were 35.3 and $75.8 \%$, respectively, for those 30-39 and 40-64 years of age in our study, which is consistent with previous reports that Chinese MSM have higher marriage and lower divorce rates than their counterparts in Western countries [1-7]. The significantly lower rate of disclosing homosexual status among married (10.2\%) and divorced (16.7\%) than single (24.2\%) and co-habiting MSM (32.6\%); the significantly lower levels of recently experienced GRSEs among those who conceal their homosexual status $(0.36 \pm 0.80)$ than those who have disclosed their homosexual status to family members $(0.68 \pm 1.18)$, might support the notion that married MSM tend to keep their homosexual status as a secret. Furthermore, the high marriage and low disclosure rate, as a defense strategy against external and internal stressors, protect Chinese MSM from experiencing conflicts or harm related to sexual minority stress, which is in agreement with previous findings in China [23] and internationally [10].

Similar to previous findings in China, we observed that Chinese MSM had higher SDS and SAS scores, but lower social support compared to their heterosexual counterparts [19]. Age, HIV infection, and number of experienced GRSEs were independent predictors of depression and anxiety symptoms, and these results are consistent with previous studies. The elderly face increasing challenges, such as isolation, more stressors, and increased health problems and disabilities, making them more likely to develop psychological problems [18, 24]. Recently experienced GSREs are direct stressors and lead to increased depression and anxiety symptoms [25, 26]. HIV infection will make them face serious physical and psychological burdens and threats, rendering them more likely to experience mental health problems [27]. We found better social support is a protective factor for SDS, consistent with the findings that better social and economic status enhances an individual's ability to cope with stressful life events and were less likely to suffer from mental health problems [28].

The currently married MSM had the highest depression symptoms and social support levels, but the lowest anxiety symptoms, and current marriage was associated with significantly decreased levels of SAS $(\beta=-0.136$, $p=0.001$ ) based on multiple linear analysis. The beneficial effect of current marriage on SAS, as well as the significantly decreased GRSE and SAS levels in MSM who did not disclose their sexual identity compared with MSM who did disclose their sexual identity, provides additional evidence that entering into marriage and keeping homosexual status a secret helps them avoid or buffer the internal and external stressors from multiple sources $[7,12]$, which in turn decrease the levels of anxiety. In contrast, reduced worry and anxiety could also serve as main causes contributing to the higher marriage rates in Chinese MSM. The highest anxiety score and the lowest social support levels in divorced MSM further confirmed the effects of losing the protective effects of marriage.

The significantly elevated SDS levels in married $(50.0 \pm 10.9)$ and divorced $(49.3 \pm 12.5)$ compared with single MSM $(46.3 \pm 11.3)$ provided some evidence that continuously struggling with numerous unique challenges related to heterosexual marriage and strong internal gender role conflict (GRC) would waste their emotional energy in maintaining a highly problematic relationship discordant with their erotic desires, resulting in unhappiness and depression [7, 12]. Current marriage or divorce was not a significant predictor for SDS in multiple analyses, which was consistent with the findings of a previous study in China [16]. Anxiety and depression symptoms usually co-exist and overlap and should be considered as a continuum spectrum of affective symptoms, with the hallmark of anxiety being worry, while lack of energy, motivation, and sadness prevail for depression. Although anxiety and depression symptoms are considered to be the two main psychological health problems of MSM, limited information is available on what symptoms or aspects are more relevant to the marriage status of MSM. We think our results are in agreement with the cognitive consistency theory that heterosexual marriage could reduce the amount of worry and the level of anxiety, but make the MSM unhappy and fraught with problems, and the dissolution of marriage make MSM more anxious [12, 29].

Considering the large number (17.8 million), high marriage rate, growing HIV epidemic, and poor mental health status among Chinese MSM [11-14, 30, 31], it is critical to help MSM navigate a balance between their own needs and the culturally normative social duties as heterosexual men. More efforts are needed to reduce the social stigma toward homosexual behaviors and external pressure to marry, targeting specific HIV-prevention and professional consult services, and skills to cope with marriage-related troubles. Early detection of anxiety and depression symptoms, and implementing pharmacologic and non-pharmacologic treatment could improve their mental health status and provide support for MSM to accept public health services. Nonetheless, more work is needed to validate our findings and to explain the mechanisms behind the "double-edged sword" effects of marriage on the mental health of Chinese MSM, and assess the possible influence of the rapid changes in lifestyle and attitude toward homosexual behaviors and/or marriage in China.

There were some limitations within this study that need to be acknowledged. The temporal misalignment between marriage status (current status), depression and 
anxiety (in the past week), GRSE (in the past 3 months), and social support (not specified), as well as the selfreported symptoms or events, may bias their associations. The cross-sectional design of this study made it impossible to determine directionality or causality between marriage status and emotional distress. The 807 MSM were selected from 4 cities in northeast China. It is not certain that our findings can be generalized to other regions of China. Previous studies noted that RDS may have included individuals who are more marginalized, have fewer resources, and/or have more time to participate in the study. Attentions should be paid to the possible selections bias when generalizing our findings to the target MSM population.

\section{Conclusion}

Age, HIV infection, and number of experienced GRSEs are independent predictors for depression and anxiety symptoms, and current marriage is associated with significantly decreased levels of anxiety symptoms among Chinese MSM. High marriage rates in Chinese MSM may play an important role in shaping the high HIV epidemic among themselves and to their wives, as well as their mental health. New interventions to control the HIV epidemic and improve mental health should accommodate the personal, social, and cultural needs of different marriage subgroups, such as policy development and environment building, to reduce social discrimination toward homosexual behaviors and marriage/co-habitation, increasing the capabilities to buffer or cope with the unique marriage-related stressors and protect themselves and their family members from psychological harm and HIV infection, screening, and early treatment of depression and anxiety. More studies are needed to understand the mechanisms underlying the effects of different marriage status on the emotional distress of Chinese MSM.

\section{Abbreviations}

MSM: Men who have sex with men; GRSE: Gay-related stressful events; SSRS: Social Support Rating Scale; SDS: Self-Rating Depression Scale; SAS: Self-Rating Anxiety Scale; GRC: Gender role conflict; RDS: Respondentdriven sampling; LNCDCP: Liaoning Provincial Center for Disease Control and Prevention; ANOVA: Analysis of variance; MD: Marriage and divorce rates; SC: Single and cohabitation; HIV: Human Immunodeficiency Virus

\section{Acknowledgments}

We thank all study participants for their co-operation and support.

\section{Authors' contributions}

GWP and LJY conceived the study design, analysis plan and data interpretation. ZSY, SL and SW performed the data analysis, interpretation, and wrote the first draft of the report. RZ, JN, YXL, HJM, LYY and LL conducted data collection, literature search, data analysis, and quality control. All authors read and approved the final manuscript.

\section{Funding}

This study was supported by Liaoning Provincial Science-Technology Department (grant number 2008225001). The funders had no role in study design, data collection and analysis, decision to publish, or preparation of the manuscript.

\section{Availability of data and materials}

The data that support the findings of this study are available from Liaoning provincial CDC but restrictions apply to the availability of these data, which were used under license for the current study, and so are not publicly available. Data are however available from the authors upon reasonable request and with permission of Liaoning provincial CDC.

\section{Ethics approval and consent to participate}

This study was conducted in accordance with the Declaration of Helsinki on ethical principles for medical research involving human subjects. The ethics committee of Liaoning Provincial Center for Disease Control and Prevention (LNCDCP) approved this study. All subjects gave written informed consent after the study objectives were explained, and all subjects were free to withdraw at any time without giving a reason.

\section{Consent for publication}

Not applicable.

\section{Competing interests}

The authors declare that they have no competing interests.

\section{Author details}

${ }^{1}$ Institute of Preventive Medicine, China Medical University, Shenyang 110122, China. ${ }^{2}$ Institute of Chronic Diseases, Liaoning Provincial Center for Disease Control and Prevention, Shenyang, China. ${ }^{3}$ Research Center for Universal Health, School of Public Health, China Medical University, No. 77 Puhe Road, Shenyang North New Area, Shenyang 110122, Liaoning, China.

Received: 8 December 2019 Accepted: 23 March 2020

Published online: 06 April 2020

\section{References}

1. Liu JX, Choi K. Experiences of social discrimination among men who have sex with men in Shanghai, China. AIDS Behav. 2006;10(Suppl):25-33.

2. Steward WT, Miège $P$, Choi KH. Charting a moral life: the influence of stigma and filial duties on marital decisions among Chinese men who have sex with men. PLoS One. 2013;8:e71778. https://doi.org/10.1371/journal. pone.0071778.

3. $\mathrm{Xu} \mathrm{J,} \mathrm{Xu} \mathrm{J,} \mathrm{Mi} \mathrm{GD,} \mathrm{et} \mathrm{al.} \mathrm{Comparison} \mathrm{of} \mathrm{AIDS} \mathrm{related} \mathrm{sexual} \mathrm{behaviors}$ between married and unmarried MSM. Chinese J Dis Control Prev. 2010;14: 404-7 [in Chinese].

4. Tang WM, Ding JP, Yang HJ, et al. Sexual behaviors and HIV/syphilis infection among men who have sex with men: a meta-analysis of data collected between 2001 and 2006 in the Chinese mainland. Chin J AIDS STD. 2008;14:471-4+88 [in Chinese].

5. Catania JA, Osmond D, Stall RD, et al. The continuing HIV epidemic among men who have sex with men. Am J Public Health. 2001;91:907-14.

6. Dubois-Arber F, Masur JB, Hausser D, et al. Evaluation of AIDS prevention among homosexual and bisexual men in Switzerland. Soc Sci Med. 1993;37: 1539-44

7. Higgins DJ. Gay men from heterosexual marriages: attitudes, behaviors, childhood experiences, and reasons for marriage. J Homosex. 2002:42:15-34.

8. Ross MW. The relationship of perceived societal hostility, conformity, and psychological adjustment in homosexual males. J Homosex. 1978:4:157-68.

9. Ross MW. Heterosexual marriage of homosexual males: some associated factors. J Sex Marital Ther. 1979:5:142-51.

10. Jarrett K. The relationship between gay-related stress and ethnicity for homosexual and bisexual males. Honors Projects. 2006;5 Available at: http:// digitalcommons.iwu.edu/psych_honproj/5.

11. Yu L, Jiang C, Na J, et al. Elevated 12-month and lifetime prevalence and comorbidity rates of mood, anxiety, and alcohol use disorders in Chinese men who have sex with men. PLoS One. 2013;8:e50762. https://doi.org/10. 1371/journal.pone.0050762.

12. Miller B. Counseling gay husbands and fathers. In: Bozett FW, editor. Gay and lesbian parents. New York: Praeger; 1987. p. 175-87.

13. Choi KH, Gibson DR, Han L, et al. High levels of unprotected sex with men and women among men who have sex with men: a potential bridge of HIV transmission in Beijing, China. AIDS Educ Prev. 2004;16:19-30. 
14. Liao M, Kang D, Tao $X$, et al. Alcohol use, stigmatizing/discriminatory attitudes, and HIV high-risk sexual behaviors among men who have sex with men in China. Biomed Res Int. 2014. https://doi.org/10.1155/2014/ 143738 PMID: 24795879

15. Wang R, Wu C, Zhao Y, et al. Health related quality of life measured by SF36: a population-based study in Shanghai, China. BMC Public Health. 2008; 8:292. https://doi.org/10.1186/1471-2458-8-292 PMID: 18710578.

16. Zheng YJ, Xu J, Zhang HB. Anxiety, depression and high-risk behaviors among men who have sex with men. Chin Ment Health J. 2005;19:699-711 [in Chinese].

17. Yu L, Li Y, Liu L, Li S, Na J, An X, et al. Association of recent gay-related stressful events and emotional distress with suicidal behaviors over 12 months in Chinese men who have sex with men. Asia Pac Psychiatry. 2018; 10(1). https://doi.org/10.1111/appy.12286 Epub 2017 Jun 21. PubMed PMID: 28636234.

18. Shu L. Self-Rating Depression Scale. Chin J Mental Health. 1993;Suppl:194-6.

19. Wu WY. Self-Rating Anxiety Scale. Chin J Mental Health. 1993;Suppl:235-8..

20. Wang XD, Wang XL, Ma H. The mental health scale revised. Chin Mental Health J. 1999;12:194-6.

21. Wang XD, Wang XL, Ma H. The mental health scale revised. Chin Mental Health J. 1999;12:235-8.

22. Xiao SY. Social support rating scale. Chin J Mental Health. 1999;Suppl:127-31.

23. Rosario M, Schrimshaw EW, Joyce $H$, et al. Gay-related stress and emotional distress among gay, lesbian, and bisexual youths: a longitudinal examination. J Consult Clin Psychol. 2002;70:967-75.

24. Xiao CL, Chen B. Study on anxiety and depression of the elderly in Xicheng District Beijing. Chinese General Practice. 2014;26:3133-6 [in Chinese].

25. Mays VM, Cochran SD. Mental health correlates of perceived discrimination among lesbian, gay, and bisexual adults in the United States. Am J Public Health. 2001;91:1869-76.

26. Meyer IH. Prejudice, social stress, and mental health in lesbian, gay, and bisexual populations: conceptual issues and research evidence. Psychol Bull. 2003:129:674-97.

27. Hu Y, Zhong XN, Peng B, et al. Comparison of depression and anxiety between HIV-negative men who have sex with men and women (MSMW) and men who have sex with men only (MSMO): a cross-sectional study in Western China. BMJ Open. 2019;9:e023498. https://doi.org/10.1136/ bmjopen-2018-023498.

28. Cohen S, Gottlieb B, Underwood L. Social relationships and health. In: Cohen S, Underwood L, Gottlieb B, editors. Measuring and Intervening in Social Support. New York: Oxford University Press; 2000. p. 3-25.

29. Bingham TA, Harawa NT, Williams JK. Gender role conflict among African American men who have sex with men and women: associations with mental health and sexual risk and disclosure behaviors. Am J Public Health. 2013;103:127-33.

30. Zhang BC, Li XF, Shi TX, et al. A rough estimate of gay/lesbian population and their infect HIV prevalence. Chin J STD/AIDS Prev Cont. 2002;8:197-9 [in Chinese]

31. Zhang BH, Zheng $Y, X u A H$, et al. Study on 1389 men who have sex with men regarding their HIV high-risk behaviors and associated factors in mainland China in 2004. Chin J Epidemiol. 2007;28:32-6 [in Chinese].

\section{Publisher's Note}

Springer Nature remains neutral with regard to jurisdictional claims in published maps and institutional affiliations.

Ready to submit your research? Choose BMC and benefit from:

- fast, convenient online submission

- thorough peer review by experienced researchers in your field

- rapid publication on acceptance

- support for research data, including large and complex data types

- gold Open Access which fosters wider collaboration and increased citations

- maximum visibility for your research: over $100 \mathrm{M}$ website views per year

At BMC, research is always in progress.

Learn more biomedcentral.com/submissions 